\title{
Avaliação em larga escala e educação inclusiva: os lugares do aluno da Educação Especial
}

\author{
Andressa Santos Rebelo* \\ Mônica de Carvalho Magalhães Kassar**
}

\section{Resumo}

O Ministério da Educação vem utilizando um sistema avaliativo com intuito de qualificar a educação nacional e oferecer subsídios para a formulação, reformulação e monitoramento das políticas educacionais. Os alunos da educação especial podem participar do processo avaliativo desde que se enquadrem na população-alvo avaliada (idade e série) e estejam devidamente registrados no Censo Escolar. Como forma de contextualizar mudanças adotadas nessas provas a partir de 2010, neste artigo objetiva-se analisar o "espaço" que os alunos público-alvo da educação especial encontram em documentos que tratam do Sistema de Avaliação da Educação Básica (Saeb) e do Exame Nacional do Ensino Médio. Para sua elaboração foram analisados documentos orientadores e relatórios do governo federal sobre essas avaliaçóes. Conclui-se que há o crescimento constante da participação dessa população nas provas e a tentativa de adequação, a cada ano, de oferecimento de atendimento especializado para sua realização. $\mathrm{O}$ presente estudo pode nos trazer pistas sobre os moldes dessas avaliaçóes que passam a ser propostos a uma parcela da população brasileira, que apesar dos importantes avanços em números de matrículas na Educação Básica, ainda não tem sua escolarização obrigatória universalizada.

Palavras-chave: Educação Especial; Avaliação da educação básica; SAEB; ENEM.

\footnotetext{
* Professor da Universidade Federal de Mato Grosso do Sul, Corumbá, Campus do Pantanal, Mato Grosso do Sul, Brasil.

** Professora da Universidade Federal de Mato Grosso do Sul, Corumbá, Campus do Pantanal, Mato Grosso do Sul, Brasil.
} 


\section{Basic educational evaluation and Inclusive Education: the places of special education students}

\section{Abstract}

The Brazilian Ministry of Education has been using an evaluation system in order to qualify the national education and offer subsidies for the formulation, reformulation and monitoring of educational policies. Special education students may participate in the assessment process as long as they fit the assessed target population (age and grade) and are enrolled in the School Census. As a way to contextualize changes adopted in these tests from 2010, this article aims to analyze the "place" that the students of special education find in documents that deal with the Sistema de Avaliação da Educação Básica - Saeb (the Brazilian Basic Education Evaluation system) and a compulsory national examination for high school - ENEM. For its elaboration, we have analyzed guiding documents and federal government reports on these evaluations. It is concluded that there is a steady increase in the participation of this population in the tests and the federal government attempt to adapt, each year, to offer specialized assistance for its accomplishment. The present study may give us clues about the models of these evaluations that are being proposed to a portion of the Brazilian population, which despite the important advances in enrollment numbers in Basic Education, has not yet become compulsory universal education.

Keywords: Special Education; Basic evaluation system; SAEB; ENEM.

\section{Pruebas en gran escala y la educación inclusiva: los sitios del alumno de la Educación Especial}

\section{Resumen}

El Ministerio de Educación Brasileño utiliza un sistema de evaluación con el fin de calificar la educación nacional y ofrecer subsidios para la formulación, reformulación y monitoreo de las políticas educativas. Los alumnos de educación especial pueden participar en el proceso de evaluación si se encuadren en la población evaluada (edad y serie) y estén debidamente registrados en el Censo Escolar. En este artículo se pretende analizar el "sitio" que los alumnos de la educación especial encuentran en documentos que tratan del Sistema de Evaluación de la Educación Básica (Saeb) y del Examen Nacional de la Enseñanza Media. Para su elaboración, se analizaron documentos orientadores e informes del gobierno federal sobre esas evaluaciones. Se concluye que existe el crecimiento constante de la participación de esa población en las pruebas y el intento de adecuación, a cada año, de ofrecimiento de atención especializada para su realización. El presente estudio puede traer huellas sobre las formas de esas evaluaciones que pasan a ser propuestos a una parcela de la población brasileña, que a pesar de los importantes avances en números de matrículas en la Educación Básica, aún no tiene su escolarización obligatoria universalizada. 
Palabras clave: Educación Especial; Evaluación de la educación básica; SAEB; ENEM.

\section{Introdução}

O tema da avaliação tem sido foco de diversos estudos, sob as mais diferentes perspectivas. A "avaliação das aprendizagens, a avaliação institucional das escolas, a avaliação do desempenho docente e a própria avaliação de políticas coexistem nos sistemas educativos" (AFONSO, 2014, p 488), indicando um terreno fértil de atenções e pesquisas. Hodiernamente, independentemente das características das realidades nacionais ou locais, "a avaliação tornou-se uma das mais importantes preocupaçôes que marcam a agenda política no campo educativo" (CORREIA, ARELARO, FREITAS, 2015, p. 1277), especialmente pelo fato de que a avaliação transformou-se em "um procedimento que vale por si mesmo" (AFONSO, 2014; CORREIA, ARELARO, FREITAS, 2015), o que promove "sua tecnicização, exacerbando o eixo técnico em detrimento das implicaçôes éticas” (Idem, p. 1277).

Como parte fundamental e fim por excelência das políticas educacionais, a avaliação apresenta-se sob um caráter "profundamente redutor e conservador, uma verdadeira 'avaliocracia neopositivista"” (AFONSO, 2014, p. 488). Para alteraçóes em resultados, países, estados e municípios elaboram políticas de responsabilização, muitas delas voltadas ao docente, como agente principal ou único dos resultados, sejam eles bons ou maus. Piña Osorio (2013), em um editorial de dossiê dedicado à temática "avaliaçóes em Larga Escala", afirma que diante de baixos resultados do México no PISA de 2013, "las autoridades del país [...] exigieron que la reforma laboral hacia el magisterio fuera respetada por los gobiernos de los estados" (p.3).

O relatório de monitoramento da educação global, Accountability in education: meeting our commitments (UNESCO, 2018), de seguimento aos compromissos registrados na Declaração de Incheon para Educação 2030, elaborado por ocasiáo do Fórum Mundial de Educação, ocorrido em 2015, apoia-se fortemente na perspectiva do Accountability, ainda que identifique a possibilidade da ocorrência de problemas com o uso de avaliaçốes e sua relação com os processos de responsabilização:

\footnotetext{
[...] mecanismos de responsabilizaçáo bem concebidos encorajam a colaboração, levando a uma educação inclusiva, equitativa e de boa qualidade; aqueles mal concebidos fornecem uma aparência de eficácia ou, pior, distorcem a educaçáo e minam o propósito para o qual foram introduzidos (UNESCO, 2018, p.11, tradução livre).
}

A despeito dos problemas identificados como decorrentes de "maus usos", organismos internacionais, envolvidos na perspectiva das avaliaçôes em larga escala e do Accountability incitam seus usos e têm consciência de que "[...] sua presença ou ausência influencia o modo como os alunos aprendem, os professores ensinam e os governos governam" (UNESCO, 2018, p.11, tradução livre).

Como afirma Freitas (2013), a literatura apresenta certo consenso de que as avaliaçôes passam a se constituir em principal referência para a identificação ou padrão da qualidade de ensino, de modo que as escolas passam a direcionar aulas e conteúdos para o que poderá ser aferido por esses procedimentos avaliativos. 
Não desconsiderando os embates sobre as características das avaliaçóes externas (BROOKE, 2013; FREITAS, 2013; AFONSO, 2014; CORREIA, ARELARO, FREITAS, 2015), entendemos que nas escolas, para as pessoas com deficiência, ter acesso ao processo avaliativo pode significar seu reconhecimento como aluno, e ter seu lugar legitimado nos sistemas comuns de ensino. Esse entendimento baseia-se no reconhecimento de que a existência de avaliaçóes impacta a organização das escolas e a forma como os alunos são percebidos.

Ao tratar da participação de alunos da educação especial na Prova São Paulo, criada pela Secretaria Municipal de Educação de São Paulo para produzir informaçôes periódicas sobre o desempenho de seus alunos e verificar efeitos de políticas e programas educacionais adotados, Raimundo (2013) constatou que a participação do público alvo da educaçáo especial em processos avaliativos externos à escola tem gerado maior comprometimento de seus profissionais com o ensino dos conteúdos curriculares e que "o desempenho obtido por esse alunado não é responsável pelas médias insatisfatórias das unidades educacionais, ideia muito difundida entre os sistemas de ensino" (p. 5).

Diversos trabalhos procuram tratar do processo de avaliaçáo de alunos da educação especial, seja com relação à avaliação diagnóstica (CORRÊA, 2013; SANTIAGO, SANTOS; MELO, 2017) ou sobre as políticas avaliativas de larga escala (CARDOSO; MAGALHÃES, 2012; SANTIAGO, SANTOS; MELO, 2017; SILVA, 2013). Essas pesquisas apontam a complexidade da avaliação na área da educação especial, no que diz respeito às políticas e práticas pedagógicas decorrentes das perspectivas das diferentes redes de ensino. No que concerne à realização de avaliação da política de Educação Inclusiva no Brasil, esta tem ocorrido considerandose indicadores concernentes às metas estipuladas no Plano Nacional de Educação (2014-2024), que acaba por privilegiar aspectos relativos ao acesso à escolarizaçáo e não, necessariamente, ao desempenho dos alunos ou ao atendimento de suas especificidades. A Unesco (2018) reconhece que a "maioria dos mecanismos nacionais de monitoramento da educaçáo inclusiva concentra-se estreitamente em matrículas, em vez de práticas em escolas e salas de aula" (p.195), o que faz supor que situaçóes semelhantes ao Brasil podem ser encontradas em outros países.

Avaliar e medir são práticas comuns na educação especial, com desdobramentos no encaminhamento de alunos para formas de atendimento e efeitos sobre aqueles considerados com problemas de aprendizagem, sem necessariamente apresentar alguma deficiência (SCHNEIDER, 1977; PASCHOALICK, 1981). No âmbito da avaliação em larga escala, estudos que focam a participação dos alunos da Educação Especial na Prova Brasil e no Exame Nacional do Ensino Médio (ENEM) revelam alguns problemas, em que se destacam

[...] o baixo número de matrículas desta população nas séries em [que] as provas são aplicadas; sua pequena participaçáo nos exames nacionais; a defasagem idade-série, principalmente na $8 \mathrm{a}$ série; a maior incidência de alunos do sexo masculino e que se declararam brancos; desempenho mediano, que não pode ser utilizado como justificativa para a não participação (SILVA; MELETTI, 2014, p. 66). 
Diante do quadro apresentado, neste artigo, objetiva-se analisar o "espaço" que os alunos público-alvo da educação especial encontram em documentos que tratam do Sistema de Avaliação da Educação Básica (Saeb) e do Exame Nacional do Ensino Médio (ENEM). Acredita-se que o presente estudo pode nos trazer pistas sobre os moldes dessas avaliaçóes que passam a incorporar uma parcela da população brasileira que, apesar de estarem no centro de importantes avanços, ainda não tem sua escolarização obrigatória universalizada (BRASIL, 2015a).

\section{Os alunos da Educação Especial no Sistema de Avaliação da Educação Básica (Saeb)}

O Sistema de Avaliação da Educação Básica (Saeb), instituído em 1990, é composto por um conjunto de avaliaçóes externas em larga escala: a Avaliaçáo Nacional da Educação Básica (Aneb), que é uma avaliação amostral que afere o desempenho de alunos das escolas públicas e privadas a cada fim de ciclo $\left(5^{\mathrm{a}}\right.$, $9^{\mathrm{a}}$ do Ensino Fundamental e $3^{a}$ do Ensino Médio), a Avaliação Nacional do Rendimento Escolar (Anresc), conhecida como Prova Brasil; e a Avaliação Nacional da Alfabetização (ANA), para aferir níveis de alfabetização e letramento em Língua Portuguesa (leitura e escrita) e Matemática. Utiliza os mesmos instrumentos da Anresc (Prova Brasil) e sua amostra é obtida por sorteio ${ }^{2}$. De acordo com o governo brasileiro, o Saeb tem como um dos seus principais objetivos "avaliar a qualidade da educação nacional e, assim, oferecer subsídios para a formulação, reformulação e monitoramento das políticas públicas educacionais" (BRASIL, 2017).

A Política Nacional de Educação Especial na Perspectiva da Educação Inclusiva (BRASIL, 2008) indica a avaliação pedagógica como processo dinâmico que deve considerar "tanto o conhecimento prévio e o nível atual de desenvolvimento do aluno quanto às possibilidades de aprendizagem futura". Segundo o documento, a avaliação configura-se como uma ação pedagógica processual e formativa que analisa o desempenho do aluno em relação ao seu progresso individual, "prevalecendo na avaliação os aspectos qualitativos que indiquem as intervençôes pedagógicas do professor". Ainda, no processo de avaliação, "o professor deve criar estratégias considerando que alguns estudantes podem demandar ampliaçáo do tempo para a realização dos trabalhos e o uso da língua de sinais, de textos em Braille, de informática ou de tecnologia assistiva como uma prática cotidiana” (BRASIL, 2008, p. 12-13).

A definição de avaliação como ação pedagógica processual não coaduna com os princípios que, via de regra, orientam as políticas avaliativas de larga escala, como "eficiência" do ensino e "fatores de influência do desempenho dos alunos" sob a forma de dados e indicadores isolados ${ }^{3}$. Ainda, o Inep não possibilita acompanhar o resultado dos alunos da educação especial, pois o acesso aos dados da Prova Brasil, nesses casos, não está aberta para análise, não sendo possível identificar tais informações (SILVA, 2013).

A partir de 2013, a legislaçáo que trata da avaliação em larga escala passa a readequar e adaptar o seu discurso frente à inclusão escolar, mesmo que para tanto passasse a delegar às escolas a disponibilização dos recursos que se fizessem necessários para a aplicação das provas: 
O Inep [Instituto Nacional de Estudos e Pesquisas Educacionais Anísio Teixeira] disponibilizará para a ediçáo da Anresc (Prova Brasil) e Aneb 2013 aplicadores a mais, para aquelas escolas que informaram, no Censo Escolar e confirmaram no agendamento da aplicação, que atendem alunos com deficiência [...]. Ficaráo inteiramente a cargo das escolas a disponibilizaçâo, aos alunos com deficiência, dos serviços de ledores, transcritores, intérpretes de Libras e guia-intérpretes, bem como a disponibilização de salas de recursos e de outros mobiliários, se necessário, para a realização das provas (INEP, 2013a, p. 8-11).

Nas orientaçôes realizadas nos anos seguintes, ocorrem mudanças nesse aspecto, o que pode ser interpretado como comprometimento do próprio Inep com as adequações necessárias à realização das avaliações por esses alunos: "é com base nos dados declarados no Censo que o Inep identifica os recursos/auxílios que serão disponibilizados aos alunos com deficiência", alertando que "informaçóes incorretas acarretarão inconsistências nos dados e problemas nas aplicações", podendo "dificultar a garantia dos direitos de plena acessibilidade aos testes para esses estudantes" (INEP, 2017a, p. 7-8).

Condiciona-se a participação de estudantes com deficiência, transtornos globais ou específicos do desenvolvimento, síndromes ou outras necessidades especiais na ANA a seu registro no Censo Escolar (BRASIL, 2016, art. $6^{\circ}$ ). Sobre essa avaliação, é descrito um número considerável de recursos para adaptação para alunos com cegueira e surdez:

[...] II - Cada estudante com cegueira será atendido em sala exclusiva e a ele serão oferecidos: a) Testes de Leitura, Escrita e Matemática adaptados em Braille; b) Profissional ledor e transcritor; c) CD com áudio para apoio aos testes. III - Cada estudante com surdez será atendido em sala exclusiva e a ele serão oferecidos: a) Testes de Leitura e de Escrita adaptados; b) Teste de Matemática em Videolibras em DVD; c) Profissional intérprete de Libras. IV Cada estudante com surdocegueira será atendido em sala exclusiva e a ele serão oferecidos: a) Testes de Leitura, Escrita e Matemática adaptados em Braille; b) Teste de Matemática em Videolibras em DVD; c) CD com áudio para apoio aos testes; d) Profissional Guia-intérprete. V - Os estudantes com baixa visão receberão testes em formato ampliado e, sempre que possível, realizarão os testes na mesma sala de sua turma regular. VI - Os estudantes que possuírem outras deficiências serão atendidos com recursos e profissionais oferecidos exclusivamente pela escola participante da avaliação. VII - Sempre que a escola considerar necessário e desde que ela informe no agendamento da aplicação, os profissionais que rotineiramente acompanham os estudantes com deficiência poderão estar presentes durante a realização dos testes (BRASIL, 2016, art. $6^{\circ}$ ).

Nesse documento, não há identificação da existência de atendimento especializado aos alunos com demais deficiências. Com relação à dispensa das provas, não fazem parte da população-alvo do SAEB 2017 "as turmas multisseriadas, de correção de fluxo, de Educação Especial Exclusiva", assim como as de "Educação de Jovens e 
Adultos, de Ensino Médio Normal/Magistério bem como as escolas indígenas que não ministrem o ensino em Língua Portuguesa” (BRASIL, 2017, art. 5º). O público descrito parece ser aquele ao qual por muito tempo as redes de ensino afirmaram apresentardificuldades em atender, aqueles alunos que não compôem, portanto, o que se considera como "educação regular".

Nos testes do Saeb 2017, as adaptaçôes parecem restringir-se ao tempo de aplicação dos testes. No item "duração da aplicação" apresenta-se o seguinte quadro:

Tabela 1 - Duração da aplicação: duração de cada um dos blocos dos testes do Saeb 2017 para as turmas com aplicação regular, as turmas com atendimento especializado a alunos com baixa visão e as turmas com atendimento especializado a alunos com outras deficiências ou transtornos

\begin{tabular}{c|c|c|c}
\hline APLICAÇĀO & REGULAR & $\begin{array}{c}\text { ATENDIMENTO } \\
\text { ESPECIALIZADO A } \\
\text { ALUNOS COM BAIXA } \\
\text { VISÄO }\end{array}$ & $\begin{array}{c}\text { ATENDIMENTO } \\
\text { ESPECIALIZADO A } \\
\text { ALUNOS COM } \\
\text { OUTRAS } \\
\text { DEFICIËNCIAS OU } \\
\text { TRANSTORNOS }\end{array}$ \\
\hline Bloco 1 & $25 \mathrm{~min}$ & $+10 \mathrm{~min}$ & $+10 \mathrm{~min}$ \\
\hline Bloco 2 & $25 \mathrm{~min}$ & $+10 \mathrm{~min}$ & $+10 \mathrm{~min}$ \\
\hline Cartão-resposta & $10 \mathrm{~min}$ & Năo preenche & $+10 \mathrm{~min}$ \\
\hline Bloco 3 & $25 \mathrm{~min}$ & $+10 \mathrm{~min}$ & $+10 \mathrm{~min}$ \\
\hline Bloco 4 & $25 \mathrm{~min}$ & $+10 \mathrm{~min}$ & $+10 \mathrm{~min}$ \\
\hline Cartão-resposta & $10 \mathrm{~min}$ & Năo preenche & $+10 \mathrm{~min}$ \\
\hline $\begin{array}{c}\text { Questionário do } \\
\text { aluno }\end{array}$ & $30 \mathrm{~min}$ & Năo responde & $+10 \mathrm{~min}$ \\
\hline TOTAL & $2 \mathrm{~h} 30 \mathrm{~min}$ & $2 \mathrm{~h} 20 \mathrm{~min}$ & $3 \mathrm{~h} 40 \mathrm{~min}$ \\
\hline
\end{tabular}

Fontes: Inep (2017a).

Anteriormente, já era registrada a preocupação em relação à diferenciação do tempo de prova. Em documento de 2015, afirma-se que "todos os alunos com deficiência que farão o Saeb em ambiente separado terão direito a tempo adicional independentemente de solicitação, podendo utilizá-lo ou náo" (INEP, 2015, p. 10).

De acordo com o Inep, o atendimento especializado deve ser orientado pelas ações do gestor da escola: 
Quadro 1 - Orientaçóes aos gestores escolares - Saeb 2017

\begin{tabular}{|c|c|c|}
\hline \multicolumn{2}{|c|}{$\begin{array}{l}\text { O QUE SERA INFORMADO/SOLICITADO AO DIRETOR NO } \\
\text { MOMENTO DO AGENDAMENTO }\end{array}$} & $\begin{array}{l}\text { O QUE O DIRETOR DA } \\
\text { ESCOLA DEVE FAZER }\end{array}$ \\
\hline \multirow{6}{*}{$\begin{array}{l}\text { Conferência de dados, } \\
\text { informados no Censo } \\
\text { Escolar, sobre alunos com } \\
\text { deficiência ou transtornos }\end{array}$} & $\begin{array}{l}\text { Quantitativo de alunos por } \\
\text { turma }\end{array}$ & \multirow[t]{2}{*}{$\begin{array}{l}\text { Consultar dados informados } \\
\text { no diário de classe }\end{array}$} \\
\hline & $\begin{array}{c}\text { Tipo de deficiência ou } \\
\text { transtorno de cada aluno por } \\
\text { turma }\end{array}$ & \\
\hline & $\begin{array}{c}\text { Disponibilidade de } \\
\text { profissional especializado na } \\
\text { escola (ledor/transcritor; leitor } \\
\text { labial/intérprete de Libras) } \\
\text { e/ou acompanhante para } \\
\text { atendimento aos alunos }\end{array}$ & \multirow{3}{*}{$\begin{array}{l}\text { - Observar o modo como } \\
\text { esses alunos são atendidos } \\
\text { no dia a dia da escola. } \\
\text { - Em caso de impossibilidade } \\
\text { de atendimento pela escola, } \\
\text { o aluno poderá participar da } \\
\text { avaliação desde que possa } \\
\text { realizá-la com sua turma e } \\
\text { sem tempo adicional. }\end{array}$} \\
\hline & $\begin{array}{l}\text { Tamanho adequado de fonte } \\
\text { das provas dos alunos com } \\
\text { baixa visão (fonte } 18 \text { ou } 24 \text { ) }\end{array}$ & \\
\hline & $\begin{array}{l}\text { Necessidade de tempo } \\
\text { adicional para esses alunos }\end{array}$ & \\
\hline & $\begin{array}{l}\text { Disponibilidade de salas } \\
\text { extras para os atendimentos } \\
\text { especializados em cada } \\
\text { turno. }\end{array}$ & $\begin{array}{c}\text { Identificar espaços } \\
\text { disponíveis, como salas de } \\
\text { aula vazias ou biblioteca. }\end{array}$ \\
\hline
\end{tabular}

Fontes: Inep (2017a, p. 15).

Por se tratar de cartilha de orientação para as escolas, as açóes são recomendadas para atenuar possíveis dificuldades. Sobre os alunos com baixa visão, prevê-se ledor/transcritor ou fontes ampliadas e para outras necessidades especiais aplicador extra:

Quadro 2 - Possibilidades de atendimento especializado para alunos com deficiência ou outras condiçóes especiais informadas no Censo Escolar

\begin{tabular}{|c|c|c|}
\hline $\begin{array}{l}\text { DEFICIENCIA/CONDIÇAO } \\
\text { ESPECIAL DO ALUNO } \\
\text { INFORMADA NO CENSO } \\
\text { ESCOLAR }\end{array}$ & $\begin{array}{c}\text { ATENDIMENTO } \\
\text { DISPONIBILIZADO PELA } \\
\text { ESCOLA }\end{array}$ & $\begin{array}{c}\text { ATENDIMENTO } \\
\text { DISPONIBILIZADO PELO } \\
\text { INEP }\end{array}$ \\
\hline \multirow[t]{2}{*}{ Baixa visão } & \multirow[t]{2}{*}{$\begin{array}{l}\text { Profissional especializado } \\
\text { (ledor/transcritor) }\end{array}$} & $\begin{array}{l}\text { Prova ampliada (fonte 18) ou } \\
\text { superampliada (fonte 24) }\end{array}$ \\
\hline & & Aplicador extra \\
\hline Outra deficiência/condição & $\begin{array}{l}\text { Profissional especializado: } \\
\text { Ledor/transcritor; Leitor } \\
\text { labial/intérprete de Libras }\end{array}$ & Aplicador extra \\
\hline
\end{tabular}

Fontes: Elaboração própria com base em Inep (2017a, p. 15). 
Preveem-se diferentes recursos a serem disponibilizados como atendimento especializado para a aplicação das provas:

Provas ampliadas (macrotipo): caderno de prova impresso em folha de papel tamanho A3, com textos de fonte tamanho 16, 18, 20 ou 24 e com imagens ampliadas. Adaptação destinada a pessoas com baixa visão.

Prova ledor: prova com auxílio de leitura oferecido por profissional ao participante com deficiência visual (cegueira ou baixa visáo). Quando necessário, a prova contém textos adaptados e descrição dos recursos visuais, não textuais, presentes na prova convencional (ilustraçóes, imagens, mapas, tabelas, gráficos, esquemas, fotografias, desenhos e símbolos). Cabe pontuar que, no caso de participantes com outras deficiências, transtornos globais do desenvolvimento, transtornos funcionais específicos ou outras condiçóes que necessitam de auxílio para leitura, é utilizada a prova comum, sem adaptação, e não a prova ledor.

Lingua Portuguesa como segunda língua para surdos (L2): caderno de prova especial impresso para alunos do $5^{\circ}$ ano/4a série do ensino fundamental, usuários da Língua Brasileira de Sinais (Libras) e que têm a Língua Portuguesa como segunda língua (L2). Nesse caderno de prova, as questôes de língua portuguesa foram adaptadas para L2. (Disponibilizado em caráter experimental na edição de 2013).

Matemática em Libras: vídeoprova em Libras, acompanhada de caderno de prova regular impresso para alunos do $5^{\circ}$ ano/4a série do ensino fundamental. (Esse recurso foi disponibilizado em caráter experimental na edição de 2013).

Tempo adicional: concedido aos alunos com deficiência que fizeram a prova em sala reservada, para a realizaçáo da prova, independentemente de solicitação prévia, podendo ser utilizado ou não, a critério do aluno. Foi concedido tempo adicional de 10 minutos para resoluçáo de cada bloco de questóes ( 40 minutos no total), de 20 minutos para preenchimento do cartáo-resposta e de 10 minutos para resposta do questionário, totalizando 1 hora e 10 minutos de tempo adicional.

Aplicador adicional: disponibilizado para acompanhamento da aplicação da prova, em sala reservada, a alunos com deficiência nas escolas que já apresentavam professores especializados para atendimento das suas necessidades, tais como: ledor, transcritor, tradutor-intérprete de Libras, leitura labial, guia-intérprete (INEP, 2018, p. 40-41)

A oferta de atendimento especializado nas provas relaciona-se com o grande número matrícula de alunos da educação especial nas escolas comuns. A figura 1 ilustra a situação em 2017. 
Figura 1 - Percentual de alunos com deficiência, transtornos globais do desenvolvimento ou altas habilidades de 4 a 17 anos incluídos em classes comuns por município - 2017

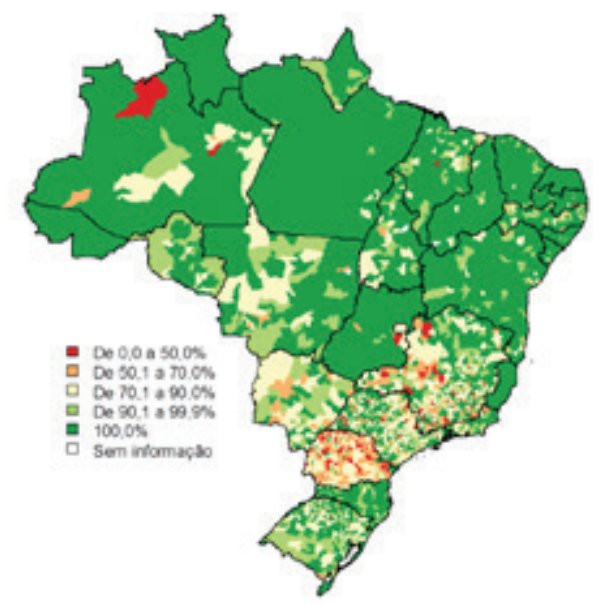

Fontes: Censo Escolar $2017^{1 .}$

Os estados do Paraná e Minas Gerais apresentam os municípios com os índices mais baixos de alunos matriculados no ensino comum. Como consequência da política nacional, que tem hegemonia em grande parte do país, um número crescente de alunos passa a frequentar os anos finais do Ensino Fundamental e o Ensino Médio. No entanto, apesar da crescente evidência de oferta de atendimento especializado para a realização das provas pelos alunos da educação especial, conseguem-se, de forma consolidada, apenas indicadores da população surda, relativos ao uso de intérpretes de LIBRAS ou de vídeo provas em LIBRAS no Exame Nacional do Ensino Médio (INEP, 2018).

\section{Alunos da Educação Especial no Exame Nacional do Ensino Médio e o acesso aos atendimentos específicos e especializados}

Pesquisas destacam o avanço recente das possibilidades de acesso ao ensino superior (ROCHA; MIRANDA, 2009) incluindo a adaptação da prova de admissão no âmbito do Exame Nacional do Ensino Médio (ENEM) (SIEMS-MARCONDES, 2018). Apesar da distância entre as políticas públicas e as formas de apoio institucional para o acesso e permanência de pessoas com deficiência nesta etapa de educação, ocorre mobilização dos espaços universitários para promover práticas inclusivas (MARTINS et al., 2017).

Estudo desenvolvido por Leria et al. (2018), com foco na população com cegueira, mostra que existem barreiras no processo atual que limitam o acesso às informaçóes e dificultam o entendimento do conteúdo do Exame Nacional do Ensino 
Médio (Enem), além de prejudicar a expressão do conhecimento por parte da pessoa com deficiência. Dos testes e dos depoimentos dos participantes com deficiência visual total, os autores concluíram que a utilização de adaptaçóes, por meio de aplicativo criado por eles, facilitaria o acesso às informaçóes do conteúdo da prova, eliminaria o esforço adicional para entendimento dos textos (falados) pelo ledor e permitiria redigir o texto e controlar a prova.

Não foram encontrados dados já compilados sobre a aplicação do Saeb para alunos público-alvo da educação especial, porém, com relação ao ENEM, na edição de 2010, inscreveram-se 17.432 pessoas com deficiência e 9.867 pessoas com mobilidade reduzida (INEP, 2013b). Já no biênio seguinte, os inscritos com deficiência ou mobilidade reduzida alcançaram, respectivamente, 21.873 e 25.107 , perfazendo um aumento de $25,5 \%$ entre 2010 e 2011 e de $14,8 \%$ entre 2011 e 2012 (BRASIL, 2015b).

Os dados sobre a participação dessas pessoas na segunda aplicação do Enem, ocorrida em 2016, revelam que se solicita atendimento especializado em diversas categorias de deficiência. Os números correspondem aos alunos (por CPF) que solicitaram atendimento especializado.

Tabela 2 - Atendimento Especializado (deficiência e/ou condição especial), por tipo e UF - Enem 2016 (Brasil)

\begin{tabular}{|c|c|c|c|c|c|c|c|c|c|c|c|c|c|c|}
\hline UF & $\begin{array}{l}\text { AUTI } \\
\text { SMOO }\end{array}$ & $\begin{array}{l}\text { BAIXA } \\
\text { VISAO }\end{array}$ & $\begin{array}{l}\text { CEGU } \\
\text { EIRA }\end{array}$ & $\begin{array}{l}\text { DEFICIE } \\
\text { NCIA } \\
\text { AUDITIN } \\
\text { A }\end{array}$ & $\begin{array}{l}\text { DEFICIE } \\
\text { NCIA } \\
\text { FISICA }\end{array}$ & $\begin{array}{c}\text { DEFICIE } \\
\text { NCIA } \\
\text { INTELE } \\
\text { CTUAAL } \\
\text { (IAENTA } \\
\text { L) } \\
\end{array}$ & $\begin{array}{c}\text { DEFI } \\
\text { CIT } \\
\text { DE } \\
\text { ATEN } \\
\text { ÇAO }\end{array}$ & $\begin{array}{l}\text { DISC } \\
\text { ALCU } \\
\text { LA }\end{array}$ & $\begin{array}{l}\text { DISL } \\
\text { EXIA }\end{array}$ & $\begin{array}{l}\text { OUTR } \\
\text { AS } \\
\text { DEFI } \\
\text { CIEN } \\
\text { CIAS }\end{array}$ & $\begin{array}{c}\text { SURD } \\
\text { EZ }\end{array}$ & $\begin{array}{l}\text { SURD } \\
\text { O- } \\
\text { CEGU } \\
\text { EIRA }\end{array}$ & $\begin{array}{c}\text { VISL } \\
\text { O } \\
\text { MON } \\
\text { OCUL } \\
\text { AR }\end{array}$ & $\begin{array}{c}\text { TOTA } \\
L \\
\text { POR } \\
\text { UF }\end{array}$ \\
\hline $\mathrm{AC}$ & - & - & - & - & - & - & - & - & - & - & - & - & - & - \\
\hline$\overline{A L}$ & 1 & 22 & 2 & 10 & 41 & 3 & 2 & - & 2 & 2 & 5 & - & 10 & 100 \\
\hline $\mathrm{AM}$ & - & - & - & - & - & - & - & - & - & - & - & - & - & - \\
\hline $\mathrm{AP}$ & - & - & - & - & - & - & - & - & - & - & - & - & - & - \\
\hline $\mathrm{BA}$ & 1 & 54 & 6 & 21 & 90 & 11 & 21 & 11 & 10 & 13 & 13 & - & 6 & 248 \\
\hline $\mathrm{CE}$ & - & - & - & - & - & - & - & - & - & - & - & - & - & - \\
\hline DF & 3 & 40 & 1 & 37 & 108 & 21 & 76 & 3 & 14 & 34 & 7 & 2 & 33 & 379 \\
\hline ES & 3 & 85 & 5 & 30 & 145 & 31 & 63 & 1 & 7 & 28 & 19 & - & 41 & 458 \\
\hline GO & 1 & 29 & - & 31 & 71 & 9 & 37 & - & 6 & 12 & 6 & - & 13 & 215 \\
\hline MA & - & - & - & - & - & - & 1 & - & - & - & - & - & - & - \\
\hline$M G$ & 10 & 104 & 11 & 69 & 176 & 22 & 138 & 14 & 27 & 47 & 16 & - & 36 & 670 \\
\hline MS & - & - & - & - & - & - & - & - & - & - & - & - & - & - \\
\hline MT & - & - & - & - & - & - & - & - & - & - & - & - & - & - \\
\hline PA & - & 21 & 2 & 8 & 43 & 1 & 4 & - & - & 7 & 10 & - & 5 & 101 \\
\hline PB & - & 4 & 1 & 1 & 9 & 1 & 1 & - & 3 & 1 & - & - & - & 21 \\
\hline PE & - & 25 & - & 30 & 53 & 6 & 69 & - & 3 & 7 & 7 & - & 16 & 216 \\
\hline $\mathrm{PI}$ & - & - & - & - & - & - & - & - & - & - & - & - & - & - \\
\hline PR & 1 & 25 & 4 & 12 & 63 & 13 & 21 & 2 & 15 & 13 & 11 & - & 22 & 202 \\
\hline RJ & 6 & 32 & 7 & 29 & 42 & 11 & 31 & 1 & 8 & 24 & 2 & - & 9 & 202 \\
\hline RN & - & 3 & - & 4 & 13 & 1 & 2 & - & - & 2 & - & - & 4 & 29 \\
\hline $\mathrm{RO}$ & - & - & - & - & - & - & - & - & - & - & - & - & - & - \\
\hline RR & - & - & - & - & - & - & - & - & - & - & - & - & - & - \\
\hline RS & - & 10 & 1 & 7 & 17 & 1 & 4 & - & - & - & - & - & 5 & 45 \\
\hline SC & - & - & - & - & - & - & - & - & - & - & - & - & - & - \\
\hline SE & 1 & - & - & - & 1 & 1 & 1 & - & - & 3 & - & - & - & 7 \\
\hline SP & - & - & - & - & - & - & - & - & - & - & - & - & - & - \\
\hline TO & - & 13 & - & 2 & 8 & 2 & 2 & - & 1 & 1 & 3 & - & 2 & 34 \\
\hline $\begin{array}{l}\text { TO } \\
\text { TAL }\end{array}$ & 27 & 467 & 40 & 291 & 880 & 134 & 473 & 23 & 96 & 194 & 99 & 2 & 202 & $\begin{array}{c}2.92 \\
8\end{array}$ \\
\hline
\end{tabular}

Fontes: MEC/Inep 2017. 
Na segunda aplicação do ENEM, realizada em 2016, predomina a solicitação de recursos para pessoas com deficiência física, seguido por pessoas com déficit de atenção, baixa visão, visão monocular, deficiência auditiva e outras deficiências. A deficiência intelectual (mental) vem em seguida (134 solicitaçóes), o que não corresponde ao conjunto dos alunos público-alvo da educação especial matriculados na educação básica, cuja categoria majoritária é a deficiência intelectual (mental) (REBELO, 2016). Em 2017, o Censo Escolar aponta que do total de 1.066 .446 matrículas de alunos público alvo da educação especial, 732.185 eram matrículas de alunos com deficiência intelectual (INEP, 2017b). Os estados com maior solicitação de atendimento especializado por deficiência são Minas Gerais, Espírito Santo e Distrito Federal.

Entre os recursos solicitados para atendimento especializado, a acessibilidade arquitetônica (sala de fácil acesso) é ressaltada:

Tabela 3 - Recursos solicitados/auxílios de atendimento - Atendimento Especializado, por tipo (Brasil) - Enem 2016.

\begin{tabular}{c|c|c}
\hline RECURSOS SOLICITADOS & TOTAL & $\%$ \\
\hline Apoio para a perna e pé & 164 & $4 \%$ \\
\hline Auxílio de ledor & 255 & $6 \%$ \\
\hline Auxílio para transcrição & 264 & $6 \%$ \\
\hline Guia-intérprete & 0 & $0 \%$ \\
\hline Intérprete de libras & 147 & $3 \%$ \\
\hline Leitura labial & 72 & $5 \%$ \\
\hline Mesa com cadeira separada & 225 & $3 \%$ \\
\hline Mesa para cadeira de rodas & 120 & $7 \%$ \\
\hline Prova ampliada & 316 & $0 \%$ \\
\hline Prova em braille & 14 & $2 \%$ \\
\hline Prova super ampliada & 77 & $\mathbf{5 5} \%$ \\
\hline Sala de fácil acesso & 733 & \\
\hline Total de solicitações de \\
recursos
\end{tabular}

Fontes: MEC/Inep $2017^{2}$

Os números de recursos demandados e os de alunos que fizeram alguma requisição são diferentes, pois um aluno poderia fazer mais que uma solicitação. Nessa fase, de $100 \%$ dos alunos que se identificaram dentre o público-alvo da educação especial, $55 \%$ optaram por solicitar recursos de acessibilidade. Entre esses, os auxílios mais requisitados foram salas de fácil acesso, seguido de prova ampliada, auxílio de ledor e auxílio para transcrição. Destaca-se que $45 \%$ dos participantes com alguma necessidade especial não solicitaram nenhum atendimento especializado. Quando se observa a porcentagem de alunos que solicita algum recurso especializado e comparamos 
com o número de alunos que têm acesso ao atendimento educacional especializado na educação básica, que em 2016 era menos de 50\% dos alunos no país (REBELO, 2016), é possível inferir que vários alunos possam desconhecer a oportunidade de acesso e uso de tais recursos. Com relação ao desempenho dos inscritos com deficiência em 2011 e 2012 tem-se:

Gráfico 1 - Distribuição dos desempenhos e das proficiências médias entre participantes por deficiência informada no ENEM - 2011-2012 (Brasil)

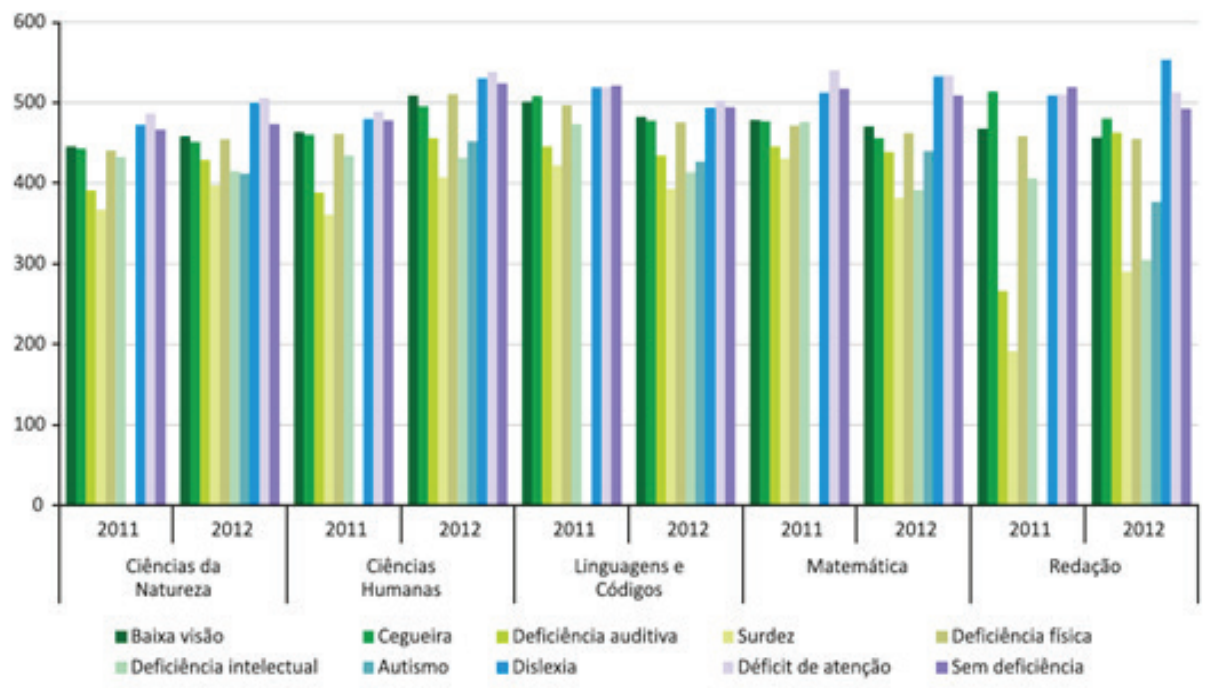

Fontes: Brasil (2015b).

Com exceção da redação em que há diferenciações mais evidentes, nas outras áreas a média de desempenho dos inscritos com deficiência equipara-se a de pessoas sem deficiência. Para que ocorram outros avanços, faz-se necessário ampliar as formas de participação das pessoas com deficiência no processo. Junqueira, Martins e Lacerda (2017) defendem que a concepção de acessibilidade em um exame não pode ficar restrita a alguns aspectos relativos à aplicação da prova, pois envolve todas as suas etapas: das Matrizes de Referência à divulgação dos resultados, passando pela produção de itens e provas acessíveis, a elaboração do edital, a criaçáo de sistema de inscrição, a seleção e a formação das equipes de campo, dos profissionais especializados e dos corretores das provas escritas, a definição dos locais de prova, dos recursos a serem disponibilizados e das sistemáticas de aplicação, e o monitoramento de cada etapa.

\section{Considerações finais}

Nesse texto procuramos analisar o "espaço" que os alunos público-alvo da educação especial encontram em documentos que tratam do Sistema de Avaliação da Educação Básica (Saeb) e do Exame Nacional do Ensino Médio. No Saeb, a ação do 
Inep oferece atendimento especializado às deficiências sensoriais (visual e surdez). No ENEM, os dados da segunda aplicação da prova em 2016 indicam que a demanda dos participantes direcionam os atendimentos. Entre os anos de 2010 e 2012 houve aumento de inscritos público-alvo da educação especial (INEP, 2013b) e dados de 2011 e 2012 demonstram que seu desempenho acompanha a média geral (gráfico 1).

No entanto, "embora crescente, o conjunto das pessoas com deficiência ainda configura um contingente reduzido", pois em 2011 e 2012 "as pessoas com deficiência representaram cerca de $0,4 \%$ em relação tanto ao total de inscritos, quanto ao de participantes" no ENEM (BRASIL, 2015b, p. 164). Essa proporção é ainda menor do que o percentual de alunos público-alvo da educação especial matriculados na educação básica no período (1,47\% em 2011 e 1,62\% em 2012) (REBELO, 2016).

Como apresentado anteriormente, há o reconhecimento de que grande parte dos mecanismos de diferentes países para monitoramento da educação inclusiva concentra-se no acesso (matrículas) e pouco se apresenta sobre as condiçôes de aprendizagem do aluno com deficiência (UNESCO, 2018). Vê-se, portanto, que este parece ser um aspecto desafiador em diferentes sistemas educacionais, de modo que no relatório sobre Accountability, no item "responsabilização pelo direito à educação inclusiva", os mecanismos apresentados pelo relatório também dizem respeito apenas ao direito de acesso: o judicial, como aprovação de leis de garantias a essa populaçáo, administrativa, por expedientes instituídos de organização e de solicitação de cumprimentos instituídos, e social, como o acompanhamento pela sociedade civil, por exemplo (UNESCO, 2018).

Dados e informaçóes específicos encontrados de forma consolidada e/ou compilada sobre a participação de alunos com deficiência no Saeb e no ENEM indicam o crescente número de alunos da Educação Especial nas diferentes etapas na educaçáo básica brasileira. Com esse aumento, o espaço desses alunos vai aparecendo e se evidenciando como necessário e relevante na consecuçáo das políticas educacionais. Destaca-se também a decorrente importância de que informaçôes sobre participação, condiçóes e desempenho sejam amplamente conhecidas e discutidas, a fim de contribuir, de fato, com o aprimoramento das políticas educacionais, sobretudo as que envolvem avaliação em larga escala; constituindo-se mais que processos estritamente técnicos, de forma a permitir a apreensáo das condiçóes de desenvolvimento educacional do país.

\section{Referências}

AFONSO, Almerindo Janela. Questôes, objetos e perspetivas em avaliação. Avaliação, Campinas; Sorocaba, SP, v. 19, n. 2, p. 487-507, jul., 2014.

BRASIL. INEP. Plano Nacional de Educaçáo PNE 2014-2024: Linha de Base. Brasília: Inep, 2015a.

BRASIL. Instituto Nacional de Estudos e Pesquisas Educacionais Anísio Teixeira. Relatório pedagógico: Enem 2011-2012. Brasília, DF: Inep, 2015b.

BRASIL. INEP. Portaria n 410, de 22 de julho de 2016. Brasília, 2016.

BRASIL. INEP. Portaria $\mathbf{n}^{\circ}$ 447, de 24 de maio de 2017. Estabelece diretrizes para o planejamento e a operacionalizaçáo do Sistema de Avaliação da Educação Básica (SAEB) no ano de 2017. Brasília, 2017.

BRASIL. MEC. SEESP. Política Nacional de Educaçáo Especial na Perspectiva da Educaçáo Inclusiva. Brasília, 2008. 
BROOKE, Nigel. Controvérsias sobre políticas de alto impacto. Cadernos de Pesquisa, v. 43, n.148, p.336347, jan./abr., 2013.

CARDOSO, Ana Paula Lima Barbosa; MAGALHÂES, Rita de Cássia Barbosa Paiva. Educação Especial e avaliaçóes em larga escala no município de Sobral (CE). Revista Educaçáo Especial, v. 25, n. 44, p. 449-464, set./dez., 2012.

CORREAA, Thaiza de Carvalho. Avaliação, diagnóstico e encaminhamento de crianças com necessidades educacionais especiais no sistema municipal de ensino de Londrina - PR. Dissertação (Mestrado em Educação). UEL, Londrina, 2013.

CORREIA, José Alberto de Azevedo e Vasconcelos; ARELARO, Lisete Regina Gomes; FREITAS, Luiz Carlos de. Para onde caminham as atuais avaliaçôes educacionais? Educaçáo e Pesquisa, São Paulo, v. 41, n. especial, p. 1275-1281, dez., 2015 .

FREITAS, Luiz Carlos de. Políticas de responsabilização: entre a falta de evidência e a ética. Cadernos de Pesquisa, v.43, n.148, p.348-365, jan./abr., 2013.

INEP. Cartilha SAEB 2017. Brasília, 2017a.

INEP. Instruçóes para aplicaçáo do Saeb 2013. Brasília, 2013a.

INEP. Instruçóes para aplicação do Sistema de Avaliação da Educação Básica (Saeb). Brasília, 2015.

INEP. Relatório SAEB (ANEB e ANRESC) 2005-2015: panorama da década. Brasília: Instituto Nacional de Estudos e Pesquisas Educacionais Anísio Teixeira, 2018.

INEP. Censo Escolar 2017: Sinopse Estatística da Educação Básica. Brasília, 2017b.

INEP. ENEM. Resultados dos participantes em 2017. Brasília, DF, 2018.INEP. Exame Nacional do Ensino Médio (Enem): relatório pedagógico 2009-2010. Brasília: O Instituto, 2013b.

JUNQUEIRA, Rogério Diniz; MARTINS, Diléia Aparecida; LACERDA, Cristina Broglia Feitosa. Política de acessibilidade e Exame Nacional do Ensino Médio (ENEM). Educ. Soc., Campinas, v. 38, n. 139, p.453-471, abr./jun., 2017.

LERIA, Lucinda de Almeida; FILGUEIRAS, Lucia Vilela Leite; SILVA, Francisco José Fraga da; FERREIRA, Leonardo Alves. ENEM Acessível: Autonomia para a Pessoa com deficiência visual total no Exame Nacional do Ensino Médio. Rev. Bras. Ed. Esp., Marília, v. 24, n. 1, p.103-120, jan./mar., 2018.

MARTINS, Sandra Eli Sartoreto de Oliveira; GOMEZ, Andrea Jimena Viera Gomez; FERNANDEZ, Yliana Zeballos; BENETTI, Caroline da Silva. Inclusão de universitários com deficiência na educação superior: o que dizem as pesquisas no Brasil e Uruguai. Jornal de Políticas Educacionais. v. 11, n. 17, nov. 2017.

PASCHOALICK, W. Análise do processo de encaminhamento de crianças das classes especiais para deficientes mentais, desenvolvido nas escolas de $1^{\circ}$ grau da delegacia de ensino de Marília. Dissertação (Mestrado em Educação). Pontifícia Universidade Católica, São Paulo, 1981.

PIÑA OSORIO, Juan Manuel. La prueba PISA del año 2013. Perfiles educativos, México, v. 36, n. 143 , p. 3-7, enero 2014 . Disponível em:<http://www.scielo.org.mx/scielo.php?script=sci_arttext\&pi$\mathrm{d}=\mathrm{S} 0185-26982014000100001 \& \operatorname{lng}=\mathrm{es} \& \mathrm{nrm}=\mathrm{iso}>$. Acesso em: 25 set. 2018.

RAIMUNDO, Elaine Alves. Avaliaçáo externa e educação especial na rede municipal de ensino de Sáo Paulo. 2013. 190 f. Dissertação (Mestrado em Educação). Faculdade de Educação. Universidade de São Paulo, São Paulo, 2013.

REBELO, Andressa Santos. A educaçáo especial no Brasil: indicadores educacionais de atendimento especializado (1973-2014). Tese (Doutorado em Educação). Universidade Federal de Mato Grosso do Sul, UFMS, Campo Grande (MS), 2016.

ROCHA, Telma Brito Rocha; MIRANDA, Theresinha Guimarães. Acesso e permanência do aluno com deficiência na instituição de ensino superior. Revista Educaçáo Especial, v. 22, n. 34, p. 197-212, maio/ago. 2009.

SANTIAGO, Mylene Cristina; SANTOS, Mônica Pereira dos; MELO, Sandra Cordeiro de. Inclusão em educação: processos de avaliação em questão. Ensaio: aval. pol. públ. Educ., Rio de Janeiro, v.25, n. 96, p. 632651, jul./set. 2017.

SCHNEIDER, Dorith. Alunos excepcionais: um estudo de caso de desvio. In: VELHO, G. (Org.). Desvio e divergência: uma crítica da patologia social. 2. ed. Rio de Janeiro: Zahar, 1977. 
SIEMS-MARCONDES, Maria Edith Romano. Estudantes com deficiência no ensino superior: trajetórias escolares, acesso e acessibilidade. Inc.Soc., Brasília, v.11, n.1, p.94-104, jul./dez., 2017.

SILVA, Mariana Cesar Verçosa; MELETTI, Silvia Márcia Ferreira. Estudantes com necessidades educacionais especiais nas avaliaçōes em larga escala: Prova Brasil e ENEM. Revista Brasileira de Educaçáo Especial, v. 20, p. 53-68, 2014

SILVA, Mariana Cesar Verçosa. Avaliaçáo em larga escala de alunos com necessidades educacionais especiais no município de Londrina-PR. Dissertação (Mestrado em Educação). UEL, Londrina, 2013.

UNESCO. The Global Education Monitoring Report. Accountability in education: Meeting our commitments. Paris: 2018.

\section{Notas}

${ }^{1} \mathrm{O}$ participante pode solicitar mais de um recurso.

${ }^{2} \mathrm{O}$ participante pode solicitar mais de um recurso.

\section{Correspondência}

Andressa Santos Rebelo - Universidade Federal de Mato Grosso do Sul, Campus do Pantanal, Rua Domingos Sahib, 99, Cervejaria, Caixa Postal 252, CEP: 79.300-130, Corumbá, Mato Grosso do Sul, Brasil.

E-mail: andressarbl@gmail.com - monica.kassar@gmail.com

Recebido em 07 de abril de 2018

Aprovado em 08 de setembro de 2018

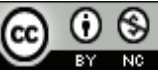

This work is licensed under a Creative Commons Attribution-NonCommercial 4.0 International (CC BY-NC 4.0) 